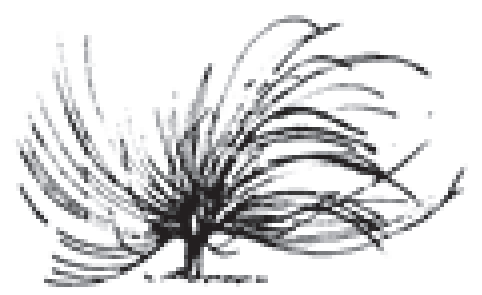

\title{
El Proyecto de Intercambio Académico y el Español como Segunda Lengua
}

\author{
Alexa Santana Umaña ${ }^{l}$ \\ Universidad Nacional \\ Heredia, Costa Rica \\ alesanum@yahoo.com
}

\begin{abstract}
Resumen
Este ensayo tiene como propósito principal contar sobre mis experiencias de la labor docente en el campo del español, como segunda lengua, que se hace dentro de la Maestría en Educación de la División de Educología, en coordinación con el Proyecto de Intercambio Académico; el cual está enfocado en la importancia de experiencias de intercambio cultural desde mi quehacer docente con estudiantes universitarios de diversas regiones de los Estados Unidos y Europa, que vienen a Costa Rica, y especialmente a la Universidad Nacional, para conocer la cultura del país y la universitaria y para mejorar sus habilidades lingüísticas en nuestra lengua.
\end{abstract}

Recibido: 19 de setiembre de 2013-Aprobado: 25 de octubre de 2014

1 Educadora, graduada de la Universidad Nacional en Bachillerato en Literatura y Lingüística con Concentración en Español y en Bachillerato en la Enseñanza del Español. Cursó sus estudios en la Licenciatura en Literatura y es egresada. Es Máster en Ciencias de la Educación con Énfasis en la Enseñanza del Español de la Universidad Latina de Costa Rica. Ha trabajado por más de 20 años como directora y docente en la enseñanza, formación, planeamiento y currículo del español como lengua extranjera. 
Palabras clave: español como segunda lengua, labor docente, cultura, habilidades lingüísticas

\begin{abstract}
This essay has the main purpose of telling my teaching experiences in the field of Spanish as a Second Language in the Master's Program in Education at "División de Educología" in conjunction with the Academic Exchange Program. This essay is focused on the importance of the cultural exchange experiences in my practice as a teacher with university students from diverse regions from the United Stated and Europe, who come to Costa Rica, and especially, to "Universidad Nacional" to know about the culture of our country and this university and to improve their linguistic skills in our language.
\end{abstract}

Keywords: Spanish as Second Language, teaching practice, culture, linguistic skills

\title{
Introducción
}

$\mathrm{E}$ n el mundo actual, con los retos de la globalización, el avance del conocimiento, y la reestructuración de los procesos educativos, junto con los nuevos contenidos, destrezas y herramientas en la formación de recursos humanos para los mercados laborales de hoy y del futuro, se considera la importancia y la necesidad de una mayor calidad y pertinencia de los programas que se ofrecen a nivel de posgrados dentro de las oportunidades educativas a nivel de enseñanza superior.

La Maestría en Educación, perteneciente a la División de Educología del Centro de Investigación y Docencia en Educación (CIDE), desde su nacimiento en el año 1995, siempre se ha preocupado por mejorar los programas que ofrece, al actualizarse constantemente ante las exigencias pedagógicas que surgen día con día. Dentro de esta constante, uno de sus tres énfasis Español como Segunda Lengua ha permitido que se extiendan nuevos conocimientos en la labor docente, pues éste es un campo inmensamente rico en donde se combinan la cultura y la lengua dentro de procesos de inmersión educativa. 
Gracias al apogeo que tiene el aprendizaje de lenguas extranjeras, y la facilidad con la que nos comunicamos e interactuamos entre países, el aprender o mejorar el idioma español ha tomado una fuerza enorme, permitiendo que muchas personas decidan viajar para experimentar y enriquecerse con todo lo que ofrece una experiencia cultural en otro país.

En estos momentos de la historia donde la comunicación y la tecnología son más accesibles dentro de la educación, los intercambios culturales están en boga al permitirles a los individuos participar en otros países de experiencias culturales, en donde aprender un idioma diferente constituye la puerta de entrada a vivir procesos de formación continua. Por esta razón, la posibilidad de participar en un programa de lengua e inmersión cultural en otro país, le amplía a cualquier persona su propia visión de mundo, al aprender, compartir, aprovechar y poner en práctica la labor docente y los conocimientos adquiridos en otra cultura.

\section{Proyecto de Intercambio Académico}

El Proyecto de Intercambio Académico surge como una acción de generar procesos de docencia, investigación, extensión universitaria y de difusión cultural, como apoyo a la administración, gestión y dirección de instituciones y programas académicos, en el marco de un proyecto o programa conjunto, entre una o más instituciones educativas o organizaciones, sobre la base de la participación de estudiantes, académicos, administradores y directivos de las instituciones educativas, buscando la cooperación internacional y la excelencia entre los participantes.

En este sentido, Pallán (2011) afirma que el intercambio académico (y la cooperación internacional), que hasta hace relativamente poco tiempo se encontraba restringido a los programas tradicionales de becas y al desarrollo de investigaciones conjuntas, ahora, con los avances en las tecnologías de comunicación, y derivado de la creciente diversidad de las organizaciones universitarias, se ha transformado en una labor compleja que involucra numerosas actividades y diversas instancias universitarias. Con la creación de proyectos de intercambio, esta labor se ha sistematizado e impulsado y ahora se reconoce como una estrategia viable para elevar la calidad de los servicios de la Educación Superior. 
Por tanto, Intercambio Académico se refiere también al proceso en donde un (a) estudiante o un (a) profesor (a) se traslada a un centro de estudios de educación superior (nacional o extranjero) para participar de una experiencia educativa en un entorno diferente. Al respecto Morales y Solís (2007), manifiestan la importancia de la participación en esta actividad académica que radica en la oportunidad de que se les da a los integrantes de vivir nuevas experiencias que permiten enriquecer el nivel profesional y académico, además expandir la forma de pensar y percibir el mundo. Además, la diversidad cultural que presenta el lugar visitado ayuda al pasante a comprender y aceptar las diferencias y la identidad cultural de los distintos grupos humanos. Así, Pallán (2011), nuevamente afirma que la experiencia ha demostrado que la diversidad de actividades de intercambio y cooperación pueden generar nuevas oportunidades de comunicación entre instituciones de origen y entornos distintos, lo que ha permitido identificar nichos de mercado para la creación de programas académicos de carácter interinstitucional con el ánimo de compartir las fortalezas de cada institución, buscando que tales actividades favorezcan a otras áreas educativas involucradas, y así favorecer el espíritu de integración.

El Intercambio Académico permite el desarrollo porque atiende a la reflexión sobre el mejoramiento de la Práctica Educativa en términos de la apropiación de la planificación de las actividades, la sistematización de observaciones, la comunicación de resultados, según lo expresa Castiblanco (2002), aspectos que dan cuenta del proceso de realimentación académica que se busca con él.

La Maestría en Educación de la Universidad Nacional tiene un proyecto adscrito llamado Proyecto de Intercambio Académico, el cual nació como un esfuerzo para responder a las exigencias y requerimientos de formación de los estudiantes de dicha maestría con sus diferentes especialidades: Énfasis en el Aprendizaje del Inglés como Lengua Extranjera, Énfasis en el Aprendizaje del Español como Segunda Lengua y Énfasis en Docencia Universitaria, para compartir espacios tanto con nativo hablantes del idioma inglés como con hispanohablantes, con el fin de que todas las partes involucradas conozcan no solamente la lengua sino también la cultura.

A partir del Énfasis en el Aprendizaje del Español como Segunda Lengua, el Proyecto de Intercambio Académico ve la necesidad de crear espacios de consolidación académica y de intercambio cultural por medio 
de pasantías a diferentes universidades, en donde estudiantes nuestros visitan centros educativos en algunos países, y estudiantes extranjeros hacen lo mismo en centros educativos costarricenses, permitiendo una participación constante y una interacción de conocimientos y vivencias únicas para ambos. Durante tiempos establecidos, alumnos de la maestría y extranjeros hacen observación de clases en preescolares, escuelas, colegios y universidades, teniendo la oportunidad de comprender las estrategias metodológicas y didácticas puestas en función por los y las docentes a cargo, al mismo tiempo que toman parte en el proceso, aportando desde su propia realidad para construir juntos esa pericia educativa para seguir creciendo como profesionales.

Pero como los procesos educativos están en constante cambio, dentro de todo este quehacer académico, se ha visto la necesidad de ampliar nuestros horizontes educativos con la consolidación de un curso especializado de Español para estudiantes extranjeros de nuestra universidad (cuya lengua materna no es el español), con un eje temático enfocado en la cultura tica. Este curso se llama Aprendizaje del Español y Cultura Costarricense y recibe a estudiantes extranjeros que estudian por un ciclo o por un año en la UNA, pero aunque hablan un poco español, todavía necesitan comprender estructuras lingüísticas y el quehacer universitario. Este curso ofrece a los y las estudiantes la oportunidad de mejorar su desempeño en el idioma mediante el uso del enfoque comunicativo, ejercitando las cuatro destrezas lingüísticas (hablar, escribir, escuchar y leer), haciendo uso de la destreza que creemos es la más importante: inmersión en nuestra cultura costarricense. Todas las actividades curriculares que se desarrollan a lo largo del curso están relacionadas con los objetivos de la clase, propiciando en el y la estudiante la participación y discusión de temas por medio de la realización de investigaciones culturales con el uso de la gramática a fin de que progresen y dominen nuestro idioma y se adapten a nuestra cultura que constituye su casa durante el tiempo de permanencia de ellos y ellas acá.

Estudiar español en Costa Rica, en la Universidad Nacional, es una experiencia única, pues los y las estudiantes llegan con la incógnita de aprender de primera mano lo que han visto en la red o lo que les han contado amigos, amigas o familiares que tuvieron la oportunidad de permanecer una temporada en este país. De hecho, uno de los insumos más grandes que tiene la constancia y permanencia de estudiantes extranjeros es porque actualmente la imagen de nuestro país se vende muy 
bien a nivel internacional debido a las enormes faenas de la Cámara de Turismo y a la Presidencia de la República. Nosotros como entidad de enseñanza superior, debemos seguir aprovechando el prestigio del que goza nuestro país para continuar mejorando nuestro proyecto, los cursos y pasantías con la intención de atraer más estudiantes y profesores/ as, hacer que los nuestros también se involucren y salgan de nuestras maestrías con ansias de seguir recibiendo más de lo que ofrecen los países que visitan.

\section{Metodología del Proyecto de Intercambio Académico}

Toda actividad de intercambio académico requiere de planes de trabajo muy elaborados, con académicos y administrativos con experiencia en lenguas extranjeras, pues estos planes tienen su propia identidad, propósitos, objetivos por competencias comunicativas, por competencias lingüísticas, actividades curriculares y extracurriculares, temas comunicativos, contenidos culturales y acciones específicas de componente sociolingüístico y sociocultural, que permiten desarrollar las tareas que se ofrecen, las propuestas y las solicitudes de las instancias de educación participantes.

Los intercambios académicos son muy ricos en actividades sociolingüísticas y culturales, ya sea, clases, conversatorios, video conferencias, chats, foros, giras, charlas, simposios, situaciones familiares, visitas guiadas, entre otras. La preparación de ellas conlleva esfuerzo, tiempo y disponibilidad de todas las partes involucradas para que cada actividad sea un éxito.

Se requiere de tiempo y pericia para planear y ejecutar cada actividad de intercambio académico, pues se debe organizar con anticipación el planeamiento de las clases, la elaboración de materiales didácticos para las finalidades específicas, los lugares propuestos, el transporte (si se requiere), las acomodaciones, las actividades culturales (visitas a teatros, museos, parques, clases de baile, talleres, actos cívicos, desfiles, procesiones, partidos de fútbol, conciertos, carreras, topes, carnavales, bodas, fiestas de cumpleaños, misas o cultos religiosos, campeonatos deportivos en el campo, la ciudad o la playa), y demás diligencias que con orden y dinamismo podrán facilitar el quehacer de enseñanza y aprendizaje, todo para que conlleve al éxito académico comunicativo, y para que cuando la experiencia concluya, nuestros (as) estudiantes puedan 
regresar a sus países para contar todo lo que aprendieron al vivir y experimentar la cultura en este nuevo hogar en el que se convirtió Costa Rica, y que le puedan llamar eternamente mi segundo hogar.

\section{Mi labor docente}

Es bastante común para mí como docente en esta área, escuchar de boca de los y las estudiantes que todas las personas del mundo deberían aprender otro idioma, porque el mundo es diverso y las posibilidades de involucrarse en otra cultura son infinitas. La mayoría de estudiantes hace intervenciones durante el desarrollo de las clases y manifiestan que les encanta la oportunidad de hablar y conocer hispanohablantes y Costa Rica es bastante popular como destino. También, la vivencia educativa universitaria es buenísima porque siempre los y las obliga a estar inmersos (as) en auténticas clases de español. Que hay diferencias con respecto al sistema educativo, por ejemplo, los planes de estudio que siguen los y las profesoras al impartir sus lecciones, y cómo sus compañeros (as) los acatan y a veces cuestionan en completa participación, pero que maduramente van aprendiendo que hay diversificación. Por esta razón, están aquí. Pero lo que más les agrada es que todos (as), absolutamente todos (as) se conocen en las clases - permitiendo una gran socialización-, gran diferencia a lo que ocurre usualmente con respecto a sus espacios académicos en sus países de origen.

Casi todos mis estudiantes vienen de Estados Unidos y de algunas partes de Europa - Alemania, Dinamarca, Austria, Suiza, entre otros - acostumbrados a la rapidez, rigidez y agilidad de todo, y cuando se enfrentan a nuestra cultura con un ritmo de vida diferente, al principio es muy difícil. Con el pasar de las semanas se van habituando y van progresando en los niveles de tolerancia hacia lo que más les sorprende de este país al principio: la hora tica, el ruido, el congestionamiento vial, los perros y gatos callejeros, el comer demasiado arroz y frijoles, los frescos naturales, el amor (y en muchos casos fanatismo) por el fútbol, la importancia de la familia y su interacción, la importancia de la religión (especialmente la católica con todos sus ritos, fiestas y ceremonias), los huecos en las calles y aceras, los piropos de parte de los hombres hacia las mujeres (la agresividad de algunos de éstos), la lentitud del internet, las clases de tres horas, los grupos de trabajo, la metodología de los profesores, las formas de diversión de jóvenes y adultos, 
y una gran lista que sería difícil de terminar. Pero que al final contribuye a que la experiencia pedagógica y cultural sea bastante buena.

Todos estos estudiantes traen como metas mejorar su discurso oral, el vocabulario coloquial, conocer al país y a la gente y disfrutar de la cultura, tener más confianza a la hora de hablar y demás. Sin embargo, se enorgullecen porque además nuestra cultura les enseña a dominar el sistema de buses, a entender el ritual de conquista, la calidez y afecto que muestran muchos (as) ticos (as), el cafecito de la tarde, la pronunciación de la "r", el ustedeo y el voseo, el lenguaje coloquial familiar y universitario, el experimentar que el país junto con su familia hospedera se levanta de madrugada, los largos aguaceros de la época lluviosa y muchísimo más.

Desde mi punto de vista docente, el enseñar el español que se habla en Costa Rica por medio de las cuatro habilidades lingüísticas, junto con el eje central que es la cultura, es toda una gran experiencia pues integralmente empieza desde el momento en que ellos se enfrentan a una cultura bastante distinta y que yo debo entender para poder ayudarlos en el proceso.

Cuando el / la profesor/a enseña Español como Segunda Lengua y Cultura, debe tener claro que la labor docente es siempre facilitar la correcta adquisición de una competencia comunicativa que le permita al y la estudiante establecer y comprender las relaciones sociales que le presenta este entorno cultural. Debe permitir que tanto él y ella se comuniquen de manera natural en español, especialmente en el discurso oral y escrito; al mismo tiempo de que manifieste opiniones e infiera a partir de lo que se aprende por medio de vivencias, vocabulario nuevo aprendido a diario y semanalmente, investigaciones, proyectos, prácticas, destrezas lingüísticas, entre otros, para que establezca, como he apuntado anteriormente, diferencias y semejanzas con su cultura de origen, siempre en un ámbito de respeto hacia la cultura anfitriona. Asimismo, debe generar un ambiente interactivo de participación para que el y la estudiante proponga actividades prácticas y creativas de la vida real que se constituyen en los recursos básicos para promover experiencias de aprendizaje.

Con cada acción metodológica se propicia en él y la estudiante extranjero (a) su capacidad de pensamiento, cooperación y tolerancia hacia él y ella mismo (a), hacia sus compañeros (as) de clase, hacia su familia tica con quien vive, en fin, hacia todo el entorno cultural que lo envuelve. 


\section{Conclusiones}

Las experiencias de intercambio académico benefician en todo aspecto mucho más de lo que una persona puede imaginarse antes de vivirlas. La capacidad de comprender las diferencias culturales es en muchos momentos crítica, pero al mismo tiempo, les permiten a las personas involucradas madurar, especialmente a los y las estudiantes que las están probando, viviendo y sintiendo. Estas experiencias promueven el respeto a la cultura donde se está hospedando, además, permiten entender la diversidad y también que no hay una cultura mejor que otra sino que solamente hay culturas diferentes.

Los ciclos universitarios en estudiantes de intercambio mejoran la visión de mundo de manera positiva, tanto que al final del proceso, ellos y ellas no quieren irse del país, de la UNA, de la familia tica, del "Pura Vida". La mayoría promete regresar y muchos (as) lo cumplen para visitar, aprender y conocer más del país, y no se arrepienten de lo vivido (aunque no todas las vivencias hayan sido positivas) pues aprendieron más de lo que piensan, ganaron conocimientos de valor para el resto de su vida, y en sus decisiones futuras, tomarán en cuenta la influencia de todas sus experiencias pedagógicas, lingüísticas y culturales que adquirieron en un programa de inmersión.

Por último, las experiencias de intercambio permitirán a los participantes ganar conocimientos que marcarán el rumbo de sus vidas y abrir puertas laborales y culturales que culminarán en beneficio personal, institucional, regional y global.

\section{Referencias bibliográficas}

Pallán, C. (2011). Las posibilidades de la Educación Superior desde la perspectiva de las redes universitarias. Recuperado de http:// www.uv.mx/cpue/coleccion/n_2728/pagina_n.htm

Castiblanco, A. (2002). Proyecto Incorporación de nuevas tecnologías. Recuperado de www.buenastareas.com

Consejo de Universidades Públicas e Instituciones afines de la ANUIES. (1999). Cooperación, movilidad estudiantil e intercambio académico. Recuperado de http://wwwold.anuies.mx/servicios/d_estrategicos/documentos_estrategicos/coop/120.html 
Morales, A. y Solís, V. (2007). Informe de Pasantía realizada a la Universidad Estatal deNuevo México. (Informe de pasantía no publicada). Universidad Nacional, Heredia. 